\title{
Orbital and Rover-Based Exploration of Perseverance Valley, Endeavour Crater, Mars
}

\author{
Ray Arvidson and the Athena Science Team
}

T206: Geomorphology and Landscape Evolution of Mars: The G. K.

Gilbert Session

$$
\text { 10/24/17 }
$$




\section{Opportunity}

Shoemaker formation impact breccias

\section{$\left\{\begin{array}{l}\text { Cape York } \\ \text { Catijevic Hill smectites, sulfates } \\ \text { Endeavour Crater }\end{array}\right.$ \\ Cook Haven Mn oxides, sulfates \\ Cape Tribulation \\ CRISM ATOS \\ Marathon Valley hematite, smectites, sulfates \\ Perseverance Valley - fluvial, debris flow, wind erosion? \\ 10/24/17 Cape Byron}

Burns formation

sufate-rich sandstones 


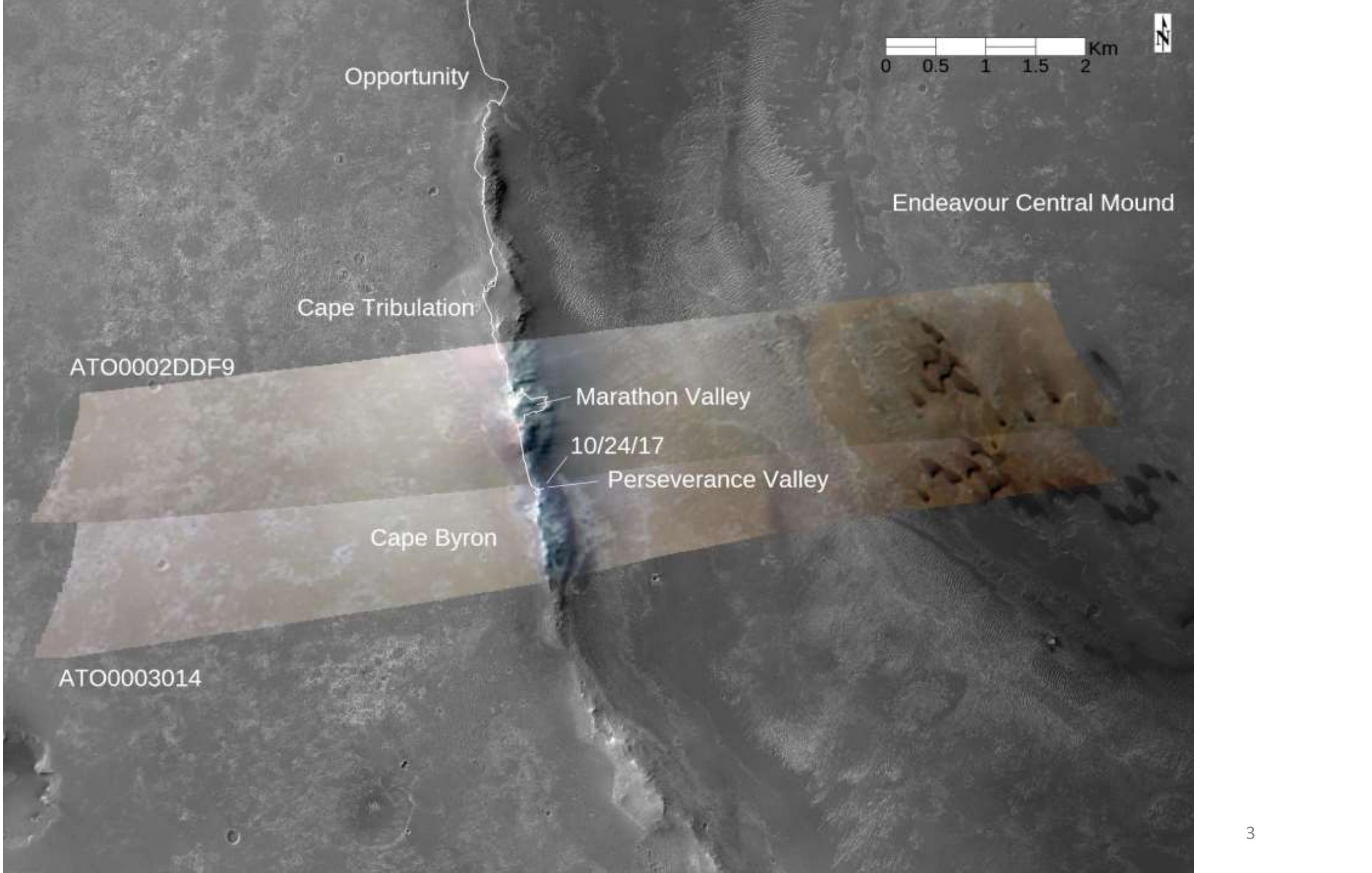




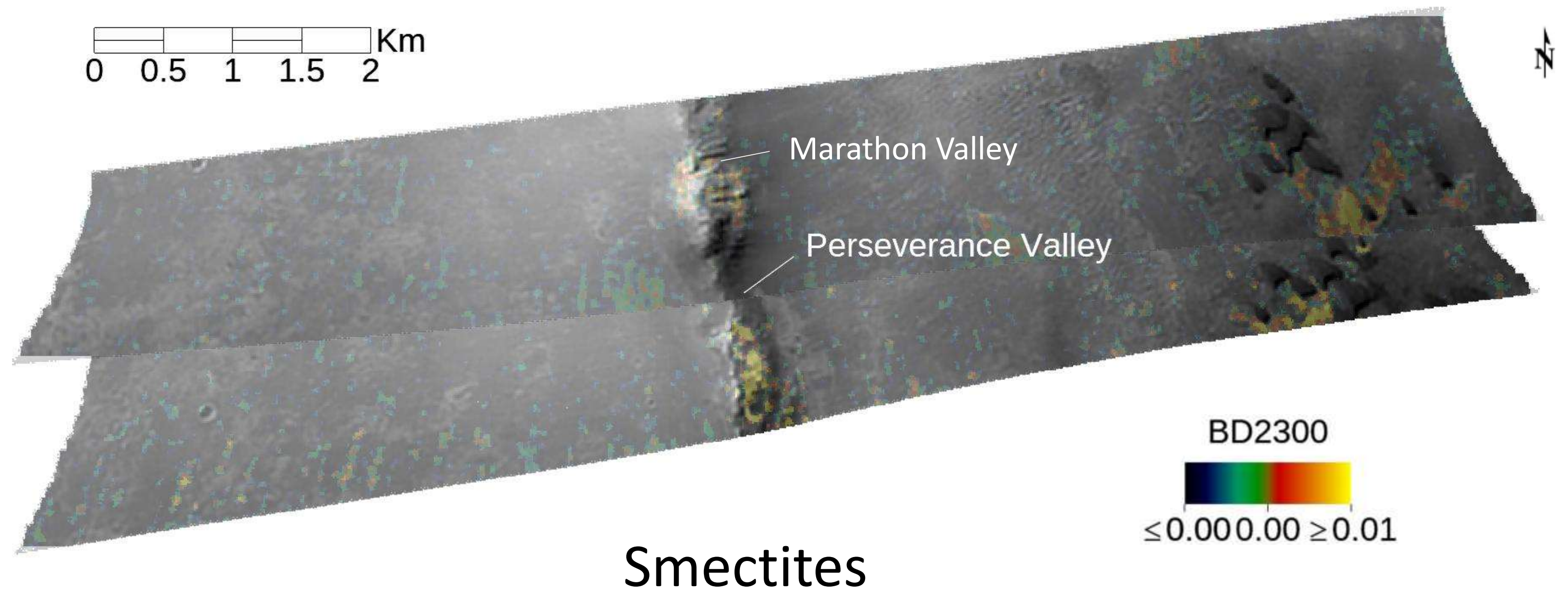




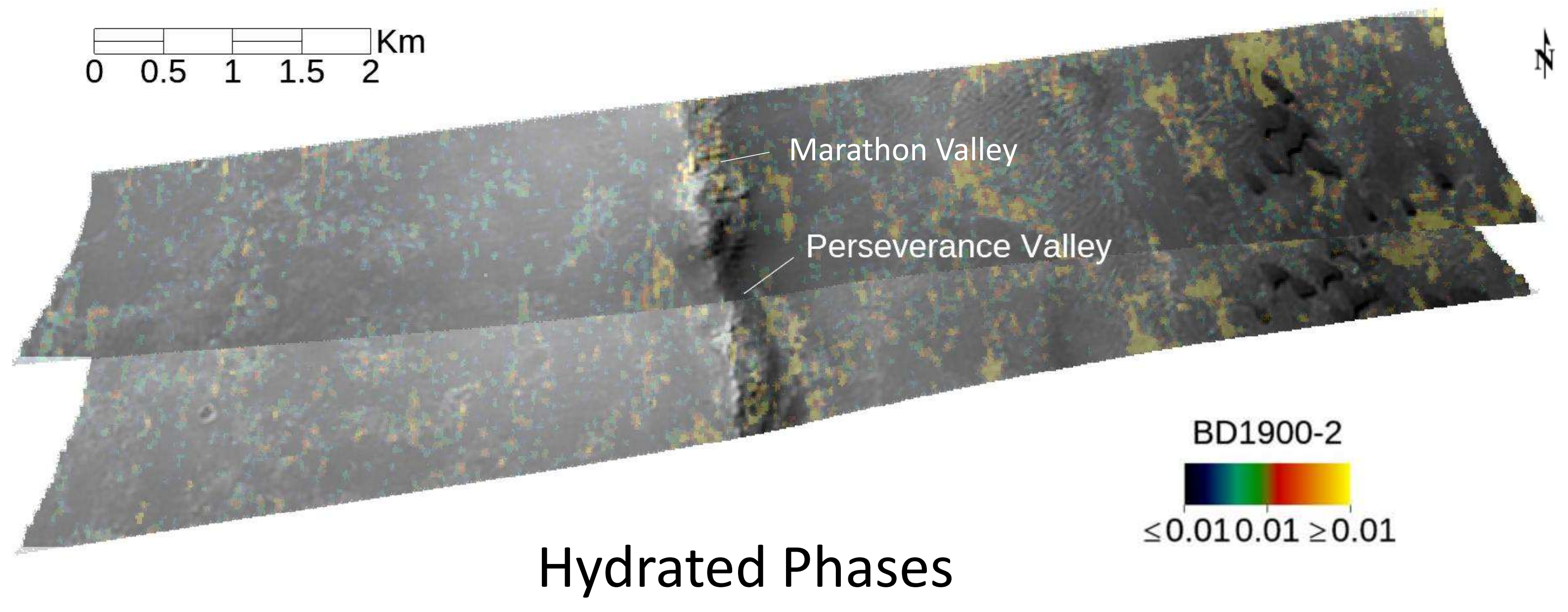




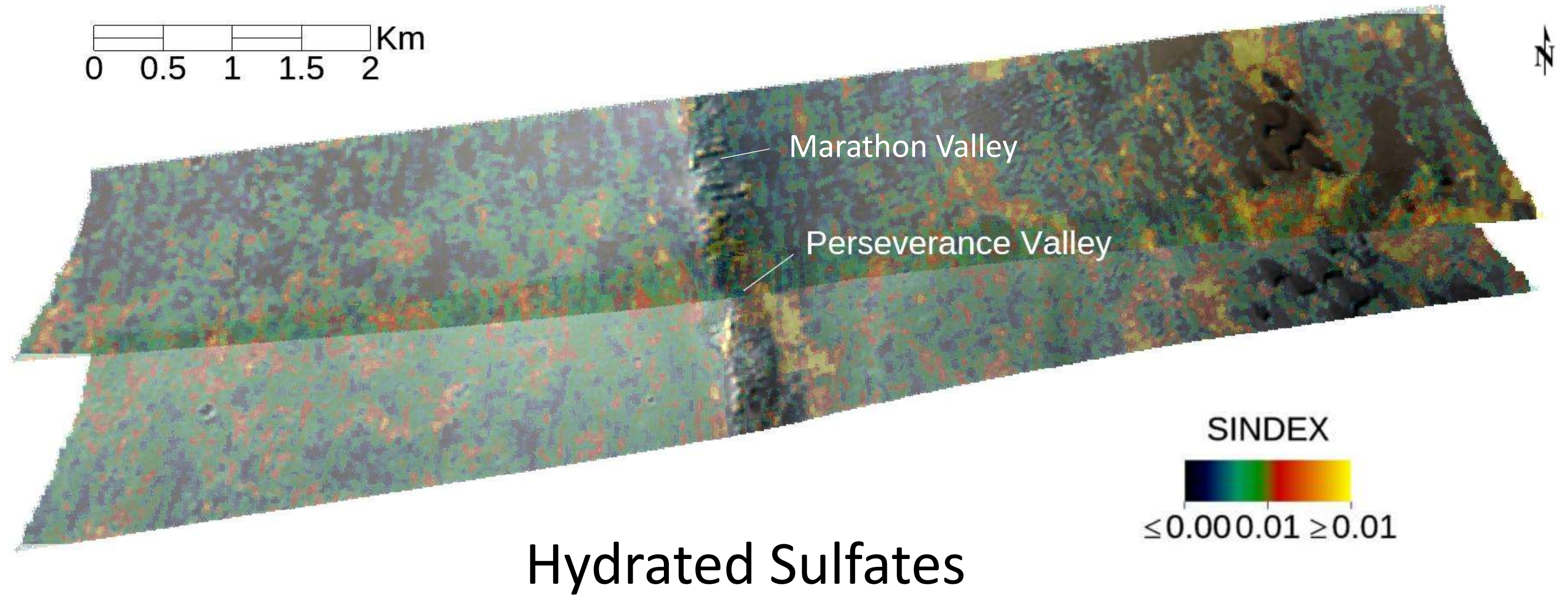




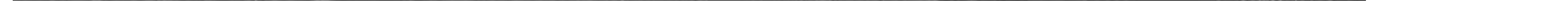




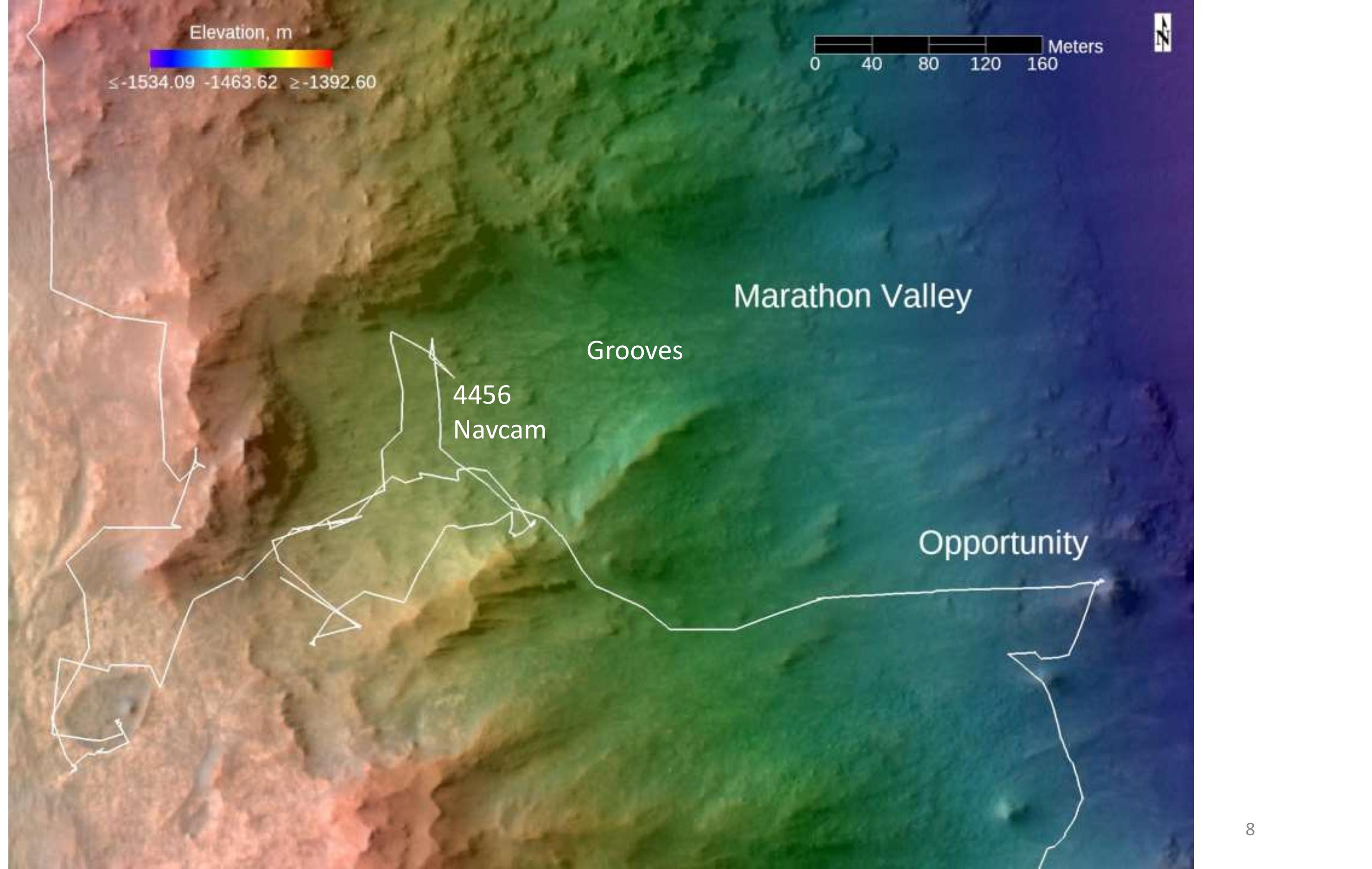




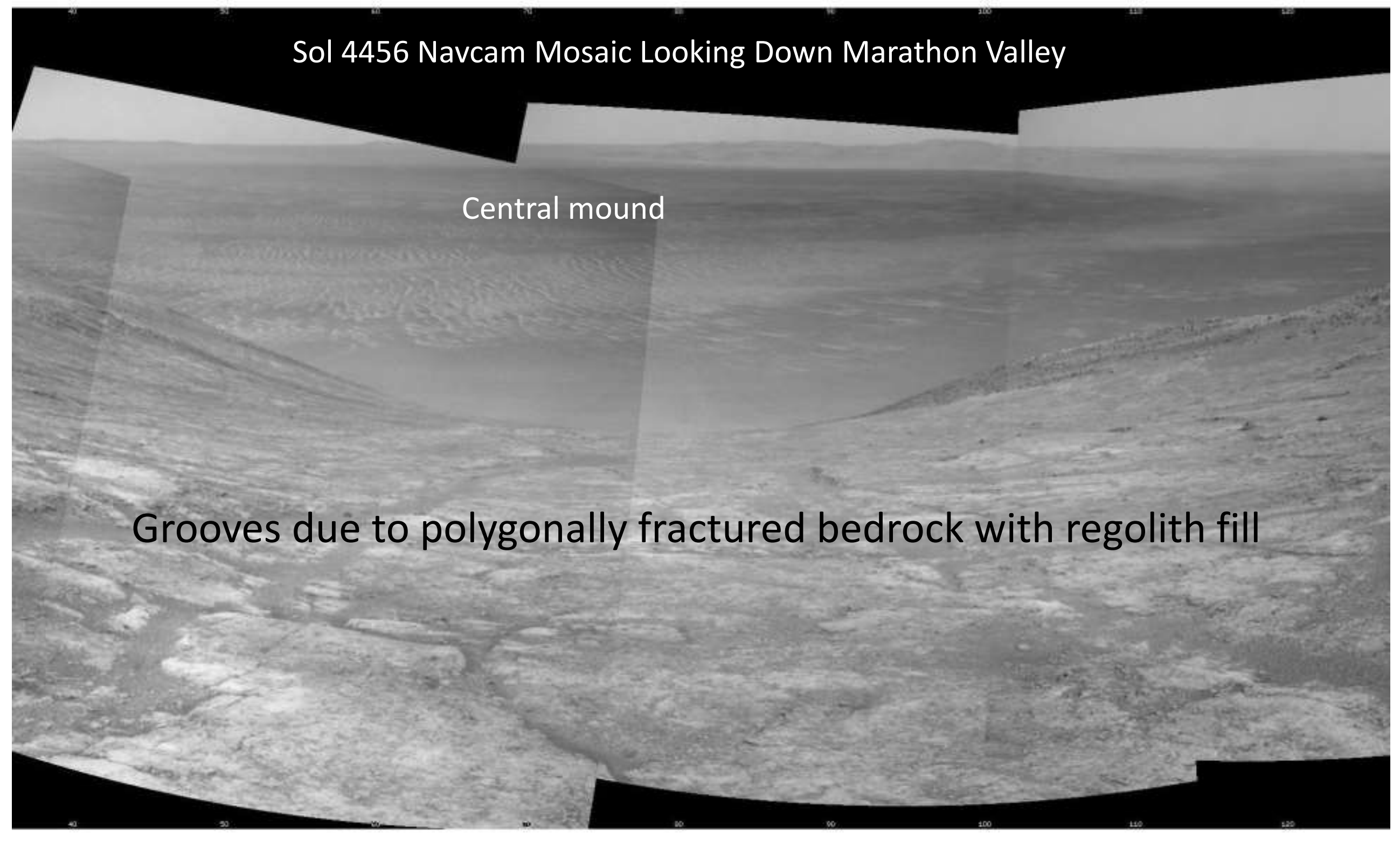


Hydrated sulfates

Perseverance Valley

Winnemucca Mesa

4754-65

Pancam "Sprained Ankle" Mosaic

Cape Byron 


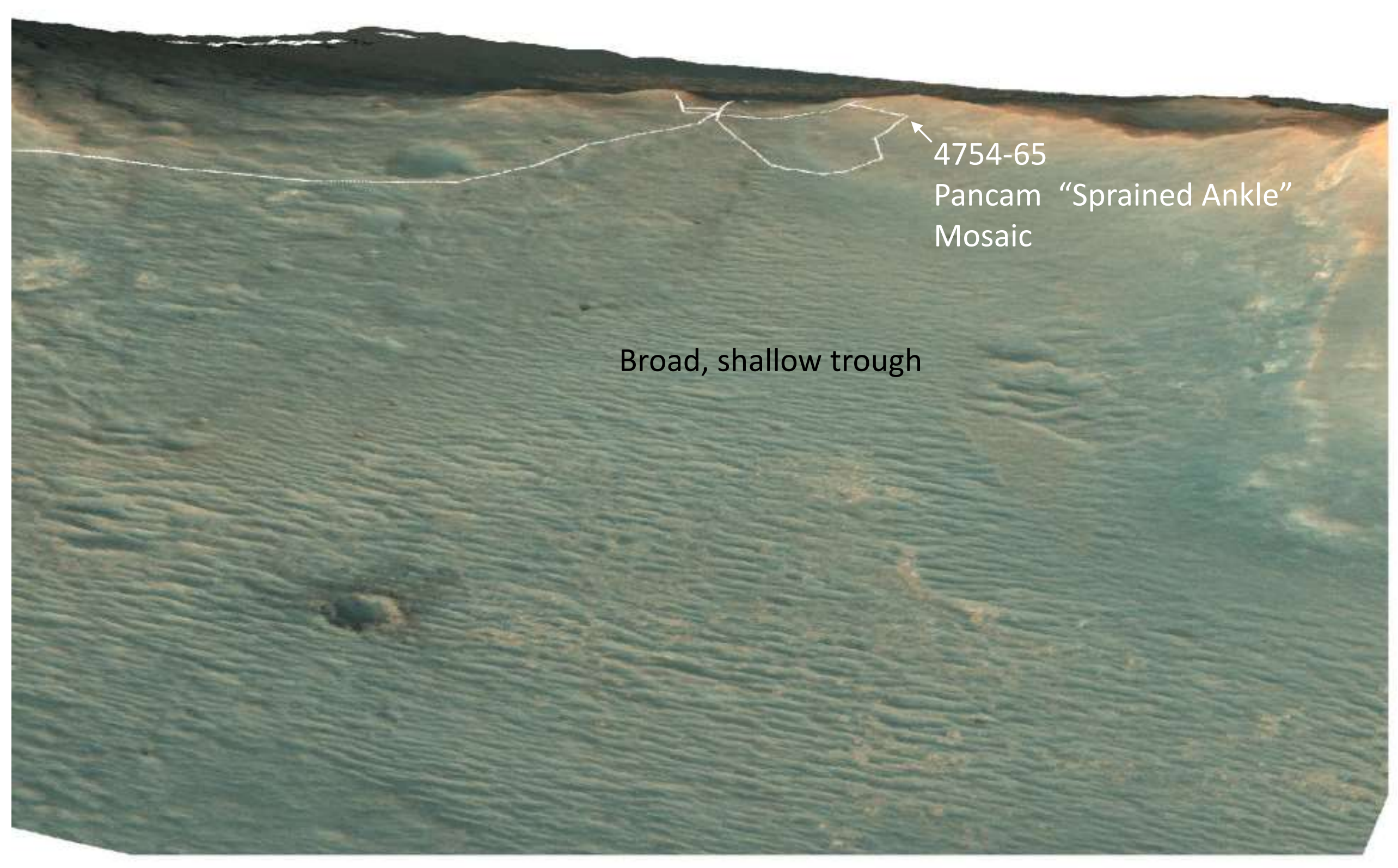




\section{Pancam Color "Sprained Ankle" Mosaic}

Upper end of broad, shallow trough

Perseverance Valley 


\section{Pancam Color "Sprained Ankle" Mosaic}

\section{Upper end of broad, shallow trough}

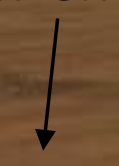

Atacama Desert debris flow deposits

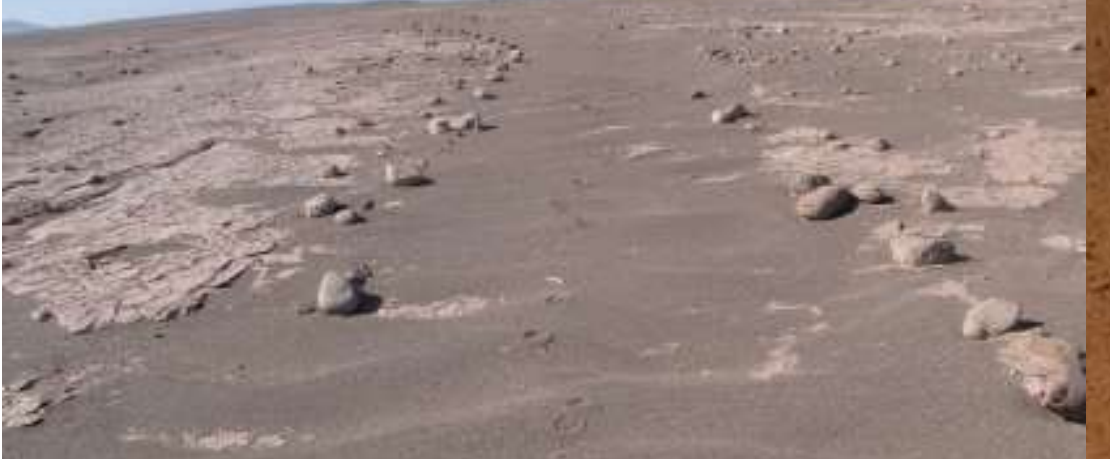

Bill Dietrich, Berkeley 
Regolith

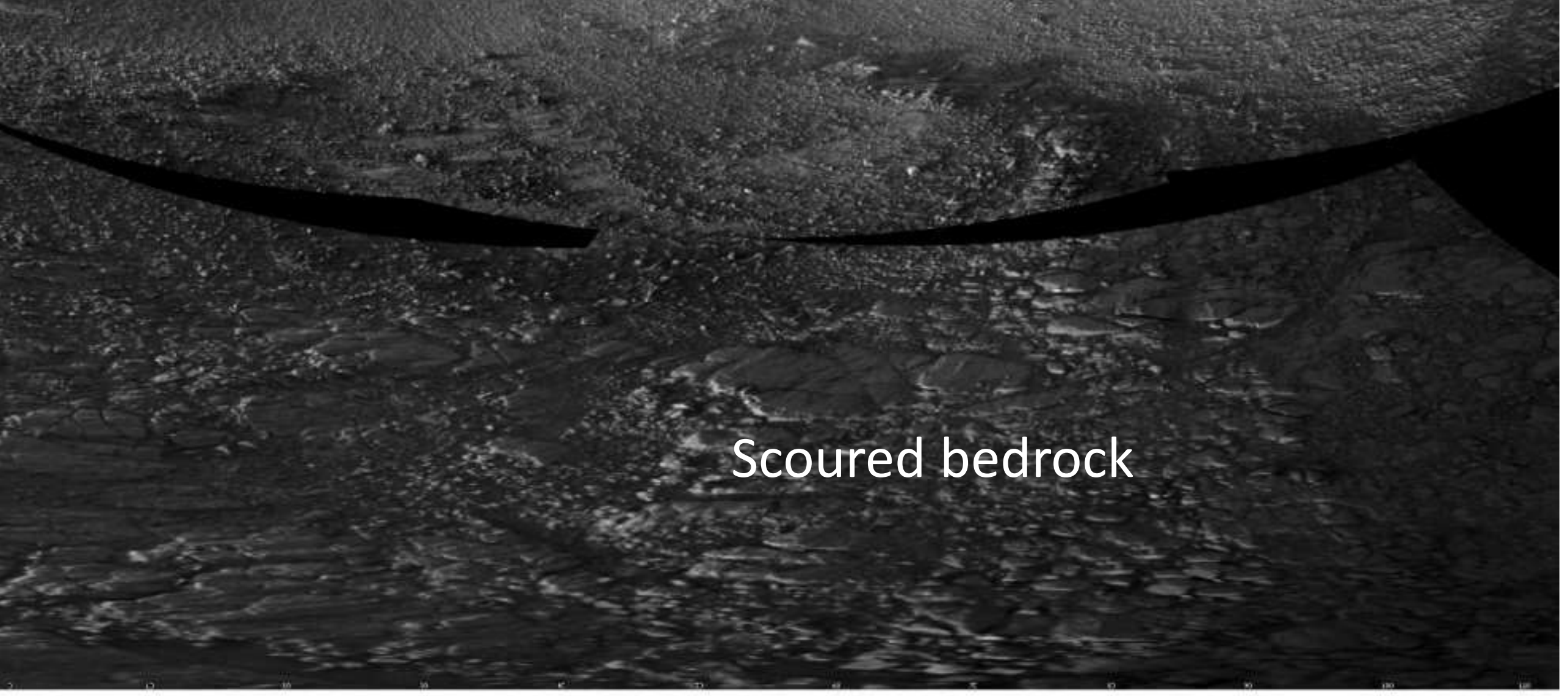




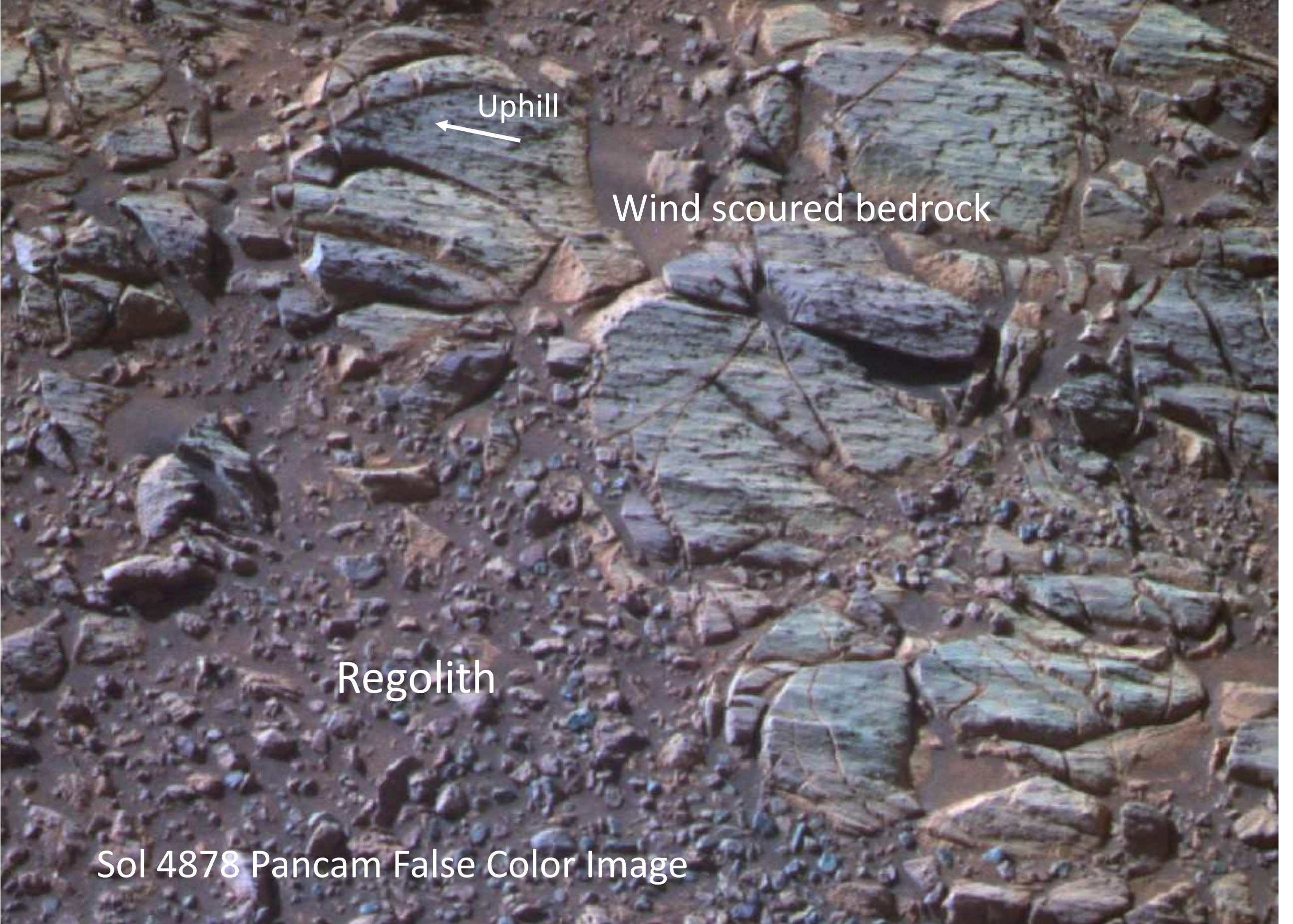


